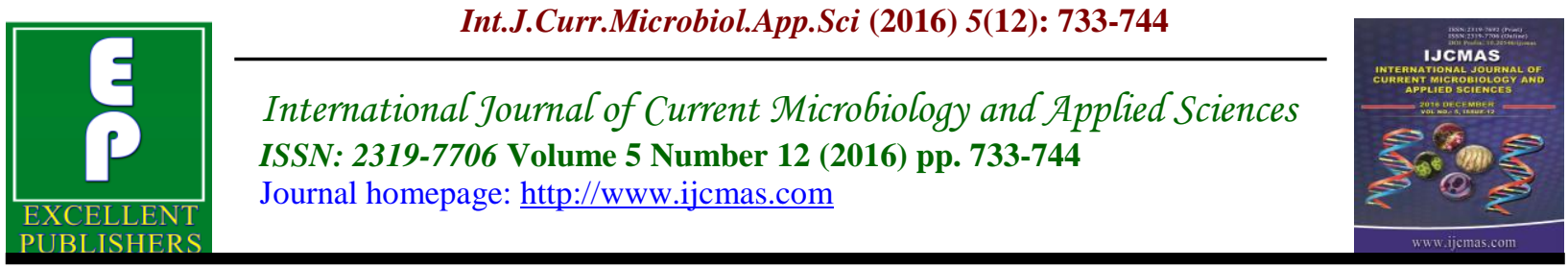

Original Research Article

http://dx.doi.org/10.20546/ijcmas.2016.512.084

\title{
Analysis of Health Care Associated MRSA and Community Acquired MRSA and its Risk Factors
}

\author{
Rajani Ranganath $^{1 *}$ and G.S. Vijaykumar ${ }^{2}$ \\ ${ }^{1}$ Department of Microbiology, Raichur Institute of Medical Sciences, Raichur, Karnataka, India \\ ${ }^{2}$ Department of Microbiology, Shridevi Institute of Medical Sciences, Tumkur, Karnataka, India \\ *Corresponding author
}

\section{Keywords}

HA-MRSA,

CA-MRSA,

Risk factors,

Antibiotic

resistance

Article Info

Accepted:

26 November 2016

Available Online:

10 December 2016

\section{A B S T R A C T}

To analyze Health care associated MRSA (HA-MRSA) and Community Acquired MRSA (CA-MRSA) strains and its risk factors. We studied the risk factors for HAMRSA and CA-MRSA infections among patients of different wards at Navodaya Medical College, Raichur, from December 2013 to November 2014. Clinical isolates of Staphylococcus isolated from nose, axilla, groin, wounds, gastrostomy tubes, endotracheal tips and inguinal areas of the patients were confirmed as Staphylococcus aureus by tube coagulase test and Methicillin resistance was detected by oxacillin broth dilution method as per CLSI guidelines. Antibiotic susceptibility profile of the community acquired and hospital acquired MRSA against a set of antibiotics was detected by Kirby bauer method. 121 strains of MRSA (24.2\%) were isolated. 91 (75\%) were HA-MRSA and $30(25 \%)$ were CAMRSA strains. Highest numbers of HA-MRSA and CA-MRSA isolates were from nose. Significant correlation $(\mathrm{P}<0.05)$ was observed between the types of MRSA, different wards, sites, and lengths of hospital stay. Antibiotic resistance rate was less in CA MRSA compared with HA MRSA isolates. $100 \%$ susceptibility to Linezolid, quinupristin/dalfopristin, tigecycline, tetracycline and cotrimoxazole was seen in all isolates of MRSA. Bacteriological confirmation of Staphylococcus aureus, MRSA and antibiotic susceptibility is very essential in the management of community acquired and hospital acquired staphylococcal infections.

\section{Introduction}

Staphylococcus aureus is one of the most significant human pathogen that causes both nosocomial and community-acquired infections (Diekema et al., 2001). Being a highly versatile and adaptable pathogen, it can cause a variety of infections of varying severity affecting the skin, soft tissue, respiratory system, bone, joints and endovascular tissues (Deleo et al., 2010). Major sites of MRSA colonization are the anterior nares of nose, wounds, tracheostomy sites, sputum of intubated patients (Walsh et al., 1987). MRSA infections are associated with high degree of mortality and morbidity and should not be disregarded totally (Warren et al., 2003).

Shortly after Methicillin was introduced into clinical practice, the first MRSA case was reported in the United Kingdom in 1961 
(Jevons, 1961). Since then, Center for Disease Control and Preventions National Nosocomial Infection Surveillance system indicates that the occurrence of MRSA infections in Indian Hospitals is increasing (CDC, 1998). Resistance occured when the organism has a mecA gene producing an altered penicillin binding protein, $\mathrm{PBP} 2 \mathrm{a}$ and either an oxacillin MIC of $2 \mathrm{mg} / \mathrm{l}$ or a methicillin MIC of $4 \mathrm{mg} / \mathrm{l}$. (Biswajit et al., 2012).

MRSA incidence varies from region to region, $25 \%$ in western part of India to $50 \%$ in south India (Patel et al., 2010; Gopalakrishnan, 2010). According to National Healthcare safety network (NHSN) 2009-2010 data, Staphylococcus isolates resistant to Methicillin is $58.7 \%$ in Catheter associated urinary tract infections(CAUTI), $54.6 \%$ in Central line associated blood stream infections (CLABSI), $48.4 \%$ in Ventillator associated pneumonia (VAP), $43.7 \%$ in surgical site infections (SSI's) (Dawn et al., 2013).

MRSA strains are subdivided as Hospital acquired MRSA (HA-MRSA) or Community acquired MRSA (CA-MRSA). HA-MRSA differs from CA-MRSA in several important ways. CA-MRSA has increased predilection for skin infections, soft tissue infections, also cause necrotising pneumonia, septic shock, bone and joint infections, are associated with PVL genes and are generally susceptible to more antibiotics. HA-MRSA is usually associated with bacteraemia, surgical wounds, open ulcers, i.v. lines, catheter urine, ventilatorassociated pneumonia, absence of PVL genes and are often multiresistant to many antibiotics including gentamicin, clindamycin, flouroquinolones (Arora et al., 2012; Defres et al., 2009). Appropriate empirical antimicrobial treatment requires regional specific information on MRSA incidence and drug susceptibility pattern
(Gorwitz et al., 2006). So we carried out this study with the aim of detecting the rates and risk factors of CA-MRSA and HA-MRSA in this hospital.

\section{Materials and Methods}

\section{Study setting}

The study was carried out in Navodaya Medical College, Raichur, from December 2013 to November 2014. A total of 500 non repetitive isolates of Staphylococcus aureus were included in the study. These isolates were obtained from various clinical samples of patients admitted in medical, surgical, pediatric wards and ICU. Medical problems suffered by these patients include urinary tract infections, aspiration pneumonia, upper gastrointestinal bleeding, gastrostomy tube placement, septicaemia, renal failure, diabetes mellitus, myocardial infarction, pulmonary edema and nephrotic syndrome. Specimens from all suspected MRSA patients were collected from nose, axillae, groin, wound, blood, tracheostomy tube. All specimens were sent to microbiology laboratory as early as possible for culture and sensitivity. Other patient details regarding basic demographics, medication history, culture site, time between admission and positive culture for MRSA, length of hospital stay and social history were meticulously recorded.

Criteria for designating the strains as CAMRSA and HA-MRSA are as follows. CA MRSA occurs in individuals in the community, who are generally healthy, who are not receiving healthcare in a hospital or on an ongoing outpatient basis and all infections occurring among the out patients or inpatients with an MRSA isolate earlier than 48 hours of hospitalization. HA MRSA refers to any MRSA which was isolated from a patient after $48 \mathrm{hrs}$ of hospitalization or from a patient with a history of 
hospitalization for surgery or dialysis or a residence in a long term care facility within 1 year of MRSA culture date (Vysakh et al., 2013).

\section{Identification of S.aureus from clinical Specimens}

Standard tests like Gram's staining, culture on blood agar and mac conkey agar incubated at $37^{\circ} \mathrm{C}$ for 24 hours, catalase test, DNase, growth on mannitol salt agar, slide and tube coagulase tests were used for identification of Staphylococcus aureus isolates (Forbes et al., 1998). Strains positive for these tests were labeled as $S$. aureus.

\section{Antibiotic Susceptibility Testing}

Antibiotic susceptibility pattern of all confirmed S.aureus strains were determined by Kirby bauer disc diffusion method (Bauer et al., 2007). Benzyl penicillin (10 units), gentamicin $(10 \mu \mathrm{g})$, ciprofloxacin $(5 \mu \mathrm{g})$, levofloxacin $(5 \mu \mathrm{g})$, clindamycin $(2 \mu \mathrm{g})$, erythromycin $(15 \mu \mathrm{g})$, quinupristin/ dalfopristin, linezolid $(30 \mu \mathrm{g})$, tigecycline $(15 \mu \mathrm{g})$, tetracycline $(30 \mu \mathrm{g}) \quad$ and cotrimoxazole $(1.25 / 23.75 \mu \mathrm{g})$, were the antibiotic discs used to study the susceptibility patterns of the isolates. All tests were performed on Muller- Hinton agar, and were interpreted after incubation for 24 hours at $37^{\circ} \mathrm{C}$. The results were categorized according to the guidelines of the Clinical Laboratory Standards Institute (CLSI, 1990). S.aureus ATCC 25923 was used as control strain for antibiotic susceptibility testing. All antibiotic discs and culture media were procured from Hi media Labs, Mumbai, India.

\section{Detection of MRSA}

Oxacillin MIC detection by Broth Macro dilution method: Decreasing concentrations of oxacillin in serial two-fold dilutions were done, ranging from $0.25-32 \mu \mathrm{g} / \mathrm{ml}$. The antibiotic was dissolved and prepared according to the manufacturer's instructions, and was diluted in Mueller Hinton broth (Himedia, Mumbai) supplemented with 2\% $\mathrm{NaCl}$ in accordance with CLSI guidelines. Isolated strains were standardized to 0.5 McFarland and were inoculated into tubes containing MHB with positive and negative controls. The tubes were incubated for 24 hours at $35^{\circ} \mathrm{C}$. The lowest concentration of oxacillin that inhibited bacterial growth visualized by the lack of visual turbidity was designated as the minimum inhibitory concentration (MIC). Isolates with their MIC levels $\leq 2 \mu \mathrm{g} / \mathrm{mL}$ were classified as oxacillin susceptible whereas MIC of oxacillin more than $8 \mu \mathrm{g} / \mathrm{ml}$ was classified as oxacillin resistant (CLSI, 1990).

Patients with nasal isolates were treated with mupirocin ointment 3 times daily for 5 days, and then they were investigated for 5 repeat sets of cultures. Patients were kept in contact isolation if they were positive for MRSA and the protocol was repeated for 3 sets again. If the cultures were still MRSA positive, then the patients were labeled as nasal carriers. Special emphasis was laid on clinical significance of all the S.aureus isolates as it can be a colonizer (Madani et al., 2002; Moreillon et al., 2005). This was done by correlating with Gram stained smear examination and correlation with the clinical history.

\section{Statitical analysis \& Ethical issues}

Data entry and analysis were performed using SPSS version 17. Fisher's Exact test was done to determine the statistical significance. A p value $<0.05$ was considered as statistically significant. The research proposal was cleared by medical faculty ethical review committee. 


\section{Results and Discussion}

Out of total 500 isolates of S.aureus obtained from different patients, 121 (24.2\%) patients had MRSA and 379 (75.8\%) patients had MSSA.

Among 121 MRSA patients, 91 (75\%) were found to have acquired MRSA during their stay in the hospital and $30(25 \%)$ were carriers of MRSA before they were admitted to the hospital (Table 1).

96 (79\%) patients were $>50$ years age group. 72 out of 91 patients with HA-MRSA and 24 out of 30 CA-MRSA were above 50 years of age which is almost $80 \%$ for both the groups. 10 MRSA patients were in the age group of $25-49$ years, 8 were in $15-24$ years, 7 were $<14$ years. Significant relationship $(\mathrm{P}<0.05)$ was found between numbers of patients of HA-MRSA, CAMRSA and different age groups.

$102(84 \%)$ MRSA patients were in the $<3$ months group, $76(75 \%)$ of whom had HAMRSA infection and $26(25 \%)$ had CAMRSA infection. 5 were in 3-6 months group, 6 were in 6-9 months group, 4 were in 9-12 months group and 4 were in $>12$ months group. Statistical significance between number of patients, HA-MRSA, CA-MRSA and the period of hospitalization was poor.

Among 108 patients from the medical ward, 81(75\%) had HA-MRSA and 27 (25\%) had CA-MRSA. All the patients from the surgical ward and ICU had HA-MRSA and all patients from pediatric ward had CAMRSA (Table 2).

169 isolates of S.aureus were obtained from the specimens taken from 121 MRSA patients. Among 70 nasal carriage patients, 49 patients had HA-MRSA and 21 patients had CA-MRSA. Out of 38 MRSA isolates obtained from groin, 32 had HA-MRSA and 6 had CA-MRSA. 10 isolates were from axilla, 15 were from wounds, 12 from blood, 8 from gatrostomy tube, 6 from endotracheal tube and 10 were from remaining sites which included bedsores, joints, rectal swab. In some patients, more than one isolate was obtained from different sites (Table 3). Significant relationship $(\mathrm{P}<0.05)$ was found between the number of HA-MRSA patients and the site of infections. However no significant relationship was found between the number of CA-MRSA and the site of infections.

All HA-MRSA isolates showed complete resistance to Benzylpenicillin and Erythromycin. We found high level of resistance to Gentamicin, Ciprofloxacin, Levofloxacin, Clindamycin in HA-MRSA isolates. All HA-MRSA isolates were completely sensitive to Linezolid, Quinupristin/ Dalfopristin, Tetracycline, Cotrimoxazole and Tigecycline (Table 4).

$100 \%$ resistance to Benzyl penicillin was seen in CA-MRSA isolates. Most of the CAMRSA isolates were sensitive to Gentamicin, Ciprofloxacin, Levofloxacin, Cotrimoxazole, Clindamycin. None of the CA-MRSA isolates were resistant to Linezolid, Quinupristin/Dalfopristin, Tetracycline and Tigecycline (Table 5).

The epidemiology, microbiology, and resistance of HA-MRSA and CA-MRSA requires further research and clarification due to the substantial burden of MRSA disease and in order to prevent its increasing incidence. Prevalence of MRSA in our study is $24.2 \%$ which is similar to findings of other studies ie $29.1 \%$ in mangalore (Pai et al., 2010), 40\% in bangalore (Sangeeta $e t$ al., 2013), 43\% in davanagere (Hanumantappa et al., 2003), 45\% in 
Chennai (Shanthi et al., 2009). MRSA prevalence varies among different countries ranging from $0.4 \%$ in Sweden to $48.4 \%$ in Belgium (Sader et al., 2010).

$75 \%$ of the patients had HA-MRSA in our study. The studies conducted in Chettinad (75.2\%) (Vysakh et al., 2013), Coimbatore (83.33\%) (Seema et al., 2010), Amravati (77\%) (Tambekar et al., 2007) showed similar figures of HA-MRSA infection.

CA-MRSA was seen in $25 \%$ of the patients. These findings correlate with the findings of Hubli (28.6\%) (Krishna et al., 2004), Chettinad (24.7\%) (Vysakh et al., 2013). Selection pressure due to overuse of antibiotics could have led to the emergence of methicillin-resistant strains of $S$. aureus in the community.

In this study MRSA infections were more commonly seen in the active age group (15$60 \mathrm{yrs}$ ) which is similar to findings reported by Karri Bauer A et al., (Karri et al., 2010). We also saw that $75 \%$ of HA-MRSA patient's were in the elderly age group. But CA-MRSA infections occurred in all the age groups.

89\% of MRSA isolates originated from medical wards in this study. Similar studies were conducted by Floriana Campanile et al., (Floriana et al., 2009), who reported that MRSA infections were highest from ICU's (53\%), followed by medical wards (34\%), which did not correlate with the findings of our study. MRSA infections can be prevented by identifying and screening MRSA carriers in these high risk wards. These findings are concordant with the findings of Kac Get al.,( Kac et al., 2000).

$41 \%$ of MRSA isolates were obtained from nasal carriers in our study. Studies conducted by Rajaduraipandi et al.,
Rajaduraipandi et al., 2006) showed nasal carriage rate as $51.9 \%$, carriage rate from conjunctiva as $40 \%$, oral $33.3 \%$, ear $14.3 \%$, tracheal $7.1 \%$, which is similar to our findings. Carrier involvement is the other risk factor which spreads the infections in hospitals, so proper hand washing procedures must be practiced regularly. 49 HA-MRSA patients had nasal carriage as compared to 21 CA-MRSA patients, which indicates that higher rates of MRSA nasal colonization is seen in the hospital environment than in the general population, which is similar to findings of Godfrey et al., (Godfrey et al., 1958). Patients with Diabetes mellitus, those on hemodialysis, IV drug abusers, patients with skin and soft tissue infections and those with HIV infection are at increased risk for carriage of Staphylococcus aureus in their anterior nares (Kluytmans et al., 1997).

Antibiotic susceptibilities of CA-MRSA vary considerably in different parts of the world (Chua et al., 2011). Sensitivity rate for Clindamycin by CA-MRSA strains is $77 \%$ which is similar to studies of Naimi et al., and Shapiro et al., (Naimi et al., 2003, Shapiro et al., 2009). In the same study Erythromycin and Cotrimoxazole susceptibility in CA-MRSA strains varied from $6-44 \%$ and $92-96 \%$ respectively, which is similar to sensitivity reports of our study.

In the present study we found CA-MRSA isolates were typically less multidrug resistant than HA-MRSA isolates as observed in other studies (Stevenson et al., 2005; CDC 1999; Herold et al., 1998; Naimi et al., 2001). Resistance to gentamicin, ciprofloxacin, levofloxacin, erythromycin and clindamycin were higher among hospital isolates when compared to community isolates, which is also seen in a study conducted at bangalore (Arora $e t$ al., 2012). All MRSA isolates were fully 
sensitive to quinupristin, linezolid, tigecycline, tetracycline, and trimethoprim/ sulfamethoxazole as reported in other studies (Arora et al., 2012; Huang et al., 2006).

Thus CA-MRSA strains had different characters than those of HA-MRSA strains, including the population affected, site of infections, risk factors, transmission and different microbiological characters such as with some antimicrobial susceptibilities (Millar et al., 2008). Diabetics, elderly age group, intravenous drug abusers, renal failure and weak immune systems were observed to be the highest risk factors in our study (Zinderman et al., 2004).

When the prevalence of MRSA increases in the community, CA-MRSA strains tend to replace HA-MRSA in health-care settings (Karri et al., 2010) making infection control measures less effective for reducing the prevalence of MRSA (Popovich et al., 2008).

At present, MRSA infections are treatable, but there is a need to prevent the spread of MRSA in community and hospital settings. FDA-approved antimicrobials for MRSA therapy are parenterally administered vancomycin, quinupristin/dalfopristin, linezolid, daptomycin, and tigecycline. Newer agents effective for MRSA treatment include the lipoglycopeptides - telavancin and oritavancin; the penicillin-binding protein-2a-targeted beta lactams ceftobiprole and ceftaroline, and a folic acid inhibitor - iclaprim (Thomas et al., 2008).

Table.1 Total number of patients with HA-MRSA and CA-MRSA

$\begin{array}{lll}\begin{array}{l}\text { Type of } \\ \text { MRSA }\end{array} & \begin{array}{l}\text { No. of } \\ \text { patients }\end{array} & \begin{array}{l}\text { Percentage } \\ (\%)\end{array} \\ \text { HA- } & 91 & 75 \\ \text { MRSA } & & \end{array}$

$\begin{array}{lll}\text { CA- } & 30 & 25 \\ \text { MRSA } & \end{array}$

Table.2 Distribution of HA-MRSA and CA-MRSA from different wards

$\begin{array}{llll}\begin{array}{l}\text { Type of } \\ \text { ward }\end{array} & \begin{array}{l}\text { HA- } \\ \text { MRSA }\end{array} & \begin{array}{l}\text { CA- } \\ \text { MRSA }\end{array} & \begin{array}{l}\text { Total no. of MRSA } \\ \text { isolates (\%) }\end{array} \\ \text { Medical } & 81 & 27 & 108(89 \%) \\ \text { Surgical } & 8 & 0 & 8(7 \%) \\ \text { Pediatric } & 0 & 3 & 3(2 \%) \\ \text { ICU } & 2 & 0 & 2(2 \%) \\ \text { Total } & 91 & 30 & 121(100 \%)\end{array}$


Table.3 Number of patients and sites of infections for HA-MRSA, CA-MRSA

$\begin{array}{llll}\begin{array}{l}\text { Site of } \\ \text { infection }\end{array} & \begin{array}{l}\text { HA- } \\ \text { MRSA }\end{array} & \begin{array}{l}\text { CA- } \\ \text { MRSA }\end{array} & \begin{array}{l}\text { Total no. } \\ \text { isolates }(\%)\end{array} \\ \begin{array}{l}\text { Nasal } \\ \text { carriage }\end{array} & 49 & 21 & 70(41 \%) \\ \text { Groin } & 32 & 6 & 38(22 \%) \\ \text { Axilla } & 5 & 5 & 10(6 \%) \\ \text { Wound } & 6 & 9 & 15(9 \%) \\ \text { Blood } & 10 & 2 & 12(7 \%) \\ \text { Gastrostomy } & 6 & 2 & 8(5 \%) \\ \text { Endotracheal } & 5 & 1 & 6(4 \%) \\ \text { Others } & 6 & 4 & 10(6 \%)\end{array}$

Table.4 Antibiotic sensitivity patterns of HA-MRSA

$\begin{array}{lll}\text { Antimicrobials tested } & \begin{array}{l}\text { No. of } \\ \text { Resistant } \\ \text { isolates } \\ \text { (n=91) }\end{array} & \begin{array}{l}\text { Resistance in } \\ \text { percentage } \\ (\%)\end{array} \\ \text { Benzylpenicillin } & 91 & 100 \% \\ \text { Gentamicin } & 60 & 66 \% \\ \text { Ciprofloxacin } & 77 & 85 \% \\ \text { Levofloxacin } & 77 & 85 \% \\ \text { Erythromycin } & 91 & 100 \% \\ \text { Clindamycin } & 86 & 95 \% \\ \text { Cotrimoxazole } & 0 & 0 \% \\ \text { Quinupristin/Dalfopristin } & 0 & 0 \% \\ \text { Linezolid } & 0 & 0 \% \\ \text { Tetracycline } & 0 & 0 \% \\ \text { Tigecycline } & 0 & 0 \%\end{array}$


Table.5 Antibiotic sensitivity patterns of CA-MRSA

$\begin{array}{lll}\text { Antimicrobials tested } & \begin{array}{l}\text { No. of } \\ \text { Resistant } \\ \text { isolates } \\ (\mathbf{n = 3 0})\end{array} & \begin{array}{l}\text { Resistance in } \\ \text { percentage } \\ (\%)\end{array} \\ \text { Benzylpenicillin } & 30 & 100 \% \\ \text { Gentamicin } & 0 & 0 \% \\ \text { Ciprofloxacin } & 12 & 40 \% \\ \text { Levofloxacin } & 12 & 40 \% \\ \text { Erythromycin } & 22 & 73 \% \\ \text { Clindamycin } & 7 & 23 \% \\ \text { Cotrimoxazole } & 0 & 0 \% \\ \text { Quinupristin/Dalfopristin } & 0 & 0 \% \\ \text { Linezolid } & 0 & 0 \% \\ \text { Tetracycline } & 3 & 10 \% \\ \text { Tigecycline } & 0 & 0 \%\end{array}$

The best effective topical MRSA decolinizing agent currently available is Mupirocin (Coates et al., 2009). Apart from mupirocin, chlorhexidine washing can also reduce the risk of MRSA infection and colonization (Mathanraj et al., 2009). Hand hygiene and screening health care takers and workers for the presence of these organisms will help in preventing the spread of pathogens.

Our study has some limitations. Because of limited resources, genotyping of the isolates couldn't be carried out to clearly discriminate between HA-MRSA and CAMRSA. New genotypic studies are needed to investigate the predominant clones of MRSA. More surveillance studies are required, to determine the specific risk factors associated with acquisition and transmission of HA-MRSA and CA-MRSA, and to establish preventive measures within the community.
However, despite of these limitations, our data represents differences between health care and community acquired isolates of MRSA. It may alert the infection control community of the need for vigilance in identification and implementation of appropriate infection control practices as they address these challenges in coming years. Health care practitioners should consider the possibilities of MRSA infection among the healthy patients without the history of nosocomial exposure. Culturing S.aureus isolates and carrying out AST on these isolates, particularly in communities with known high rates of MRSA infection, is very important to ensure appropriate antibiotic therapy is given. Health care practitioners should judiciously use the antibiotics in the outpatient settings to avoid expanding the spectrum of antibiotic resistance among the strains of CA-MRSA. 
In conclusion, it could be stated that the wide-spread of community and nosocomial MRSA infections stems from lack of awareness of severity of the problem among medical and paramedical staff. It is important to determine the difference of these two strains to effectively to prevent, treat, and handle patients. Follow-up of discharged patients to measure MRSA cultures and sensitivities is more important than ever. Screening can help reduce the incidence of MRSA in hospital admissions to avoid outbreaks and worldwide pandemics. Since the complete eradication of MRSA might not be possible, control of transmission seems to be the only hope. The first and the most effective way to control MRSA is good hand hygiene to reduce nosocomial rates of infection, along with environmental cleaning between patients.

\section{Acknowledgments}

The authors would like to express their profound gratitude to all the participants for the cooperation and for the immense faith the participants reposed in them.

\section{Conflict of Interest: None to declare}

Ethical Approval: Approval for study was passed from the institutional board of study meeting.

\section{References}

Arora, N., Shantala, G.B., Nagarathnamma, T. 2012. Study Of Community AcquiredMethicillin Resistant Staphylococcus aureus(CA-MRSA) Infections and Their Antibiotic Sensitivity Pattern. Nat. J. Lab. Med., 1: 15-19.

Bauer, A.W., Kirby, W.M.M., Sherris, J.C. 2007. Antibiotic susceptibility testing by a single disc method. American $J$. Pathol., 45: 493-496.
Biswajit Batabyal, Gautam, K.R. Kundu and Shibendu Biswas. 2012. MethicillinResistant Staphylococcus aureus: A Brief Review. Int. Res. J. Biol. Sci., 7: 65-71.

BVS Krishna, Asha, B., Patil and M.R. Chandrasekhar. 2004. Community acquired MRSA infections in a south Indian city. Southeast Asian J. Trop. Med. Public Health; 35, 2:371-4.

Centers for Disease Control and Prevention. 1999. Four pediatric deaths from community-acquired methicillinresistant Staphylococcus aureusMinnesota and North Dakota, 19971999. Morb. Mortal. Wkly. Rep., 48: 707-710.

Centre for Disease Control and Prevention. National Nosocomial Infection Surveillance system Data, 1989-1998. Atlanta, Ga: Centre for Disease Control and Prevention; 1998.

Chua, K., F. Laurent, G. Coombs, M.L. Grayson, B.P. Howden. 2011. "Not community-associated methicillinresistant Staphylococcus aureus (CAMRSA)! A clinician's guide to community MRSA-its evolving antimicrobial resistance and implications for therapy," Clin. Infect. Dis., 52,1: 99-114.

Coates, T., Bax, R., Coates, A. 2009. Nasal decolonization of Staphylococcus aureus with mupirocin: strengths, weaknesses and future prospects. $J$. Antimicrobial Chemother., 64,1: 9-1.

Dawn, M., Sievert, Philip Ricks, Jonathan, R., Edwards, Amy Schneider, Jean Patel, Arjun Srinivasan, Alex Kallen, Brandi Limbago, Scott Fridkin and for the National Healthcare Safety Network (NHSN) Team and Participating NHSN Facilities. AntimicrobialResistant Pathogens Associated with Healthcare-Associated Infections: Summary of Data Reported to the National Healthcare Safety Network at the Centers for Disease Control and Prevention, 2009-2010NHSN update, 
Infection Control Hospital Epidemiol., 34: 1 .

Defres, S., C. Marwick and D. Nathwani., MRSA as a cause of lung infection including airway infection, community acquired pneumonia and hospitalacquired pneumonia. European Respiratory J., 34,6: 1470-1476.

Deleo, F.R., Otto, M., Kreiswirth, B.N., Chambers, H.F. 2010. Communityassociated methicillinresistant Staphylococcus aureus. Lancet, 375: 1557-68.

Diekema, D.J., Pfaller, M.A., Schmitz, F.J., Smayevsky, J., Bell, J., Jones, R.N., Beach, M. 2001. Survey of infection due to Staphylococccus species: frequency of occurrence and antimicrobial susceptibility of isolates collected in the Unites States, Canada, Latin America, Europe, and the Western Pacific region for the sentry Antimicrobial Surveillance Program 1997-1999. Clin. Infect. Dis., 32, 114132.

Floriana Campanile, Dafne Bongiorno, Sonia Borbone, Stefania Stefani. Hospital associated methicillin resistant Staphylococcus aureus (HAMRSA) in Italy. Annals of Clin. Microbiol. Antimicrobials, 8, 22: 1-10.

Forbes, B.A., Sahm, D.F., Weissfeld, A.S. 1998. Staphylococcus, Micrococcus, and similar organisms in Forbes BA, Sahm DF, Weissfeld AS, Bailey \& Scott's Diagnostic Microbiology,10th ed. St Louis: Mosby; 1998,607-18.

Godfrey, M.E., Smith, I.M. 1958. Hospital hazards of Staphylococcal sepsis. $J$. American Med. Assoc., 166,10: 11971201.

Gopalakrishnan, R., Sureshkumar, D. 2010. Changing trends in antimicrobial susceptibility and hospital acquired infections over an 8 year period in a tertiary care hospital in relation to introduction of an infection control programme. $J$. Association of Physicians of India, 58: 25-31.
Gorwitz, R.J., D.B. Jernigan, J.H. Powers, J.A. Jernigan and Participants., Stratergies for clinical management of MRSA in the community: summary of an expert's meeting convened by the CDC. Centers of Disease Control and Prevention, Atlanta, GA.

Hanumantappa, A.R., Chandrappa, N.R., Rajasekharappa, M.G. 2003. Prevalence of methicillin resistant Staphylococcus in

Karnataka. Indian J. Pathol. Microbiol., 46,1: 129-32.

Herold, B.C., Immergluck, L.C., Maranan, M.C., Lauderdale, D.S., Gaskin, R.E., Boyle-Vavra, S., Leitch, C.D., Daum, R.S. 1998. Community acquired methicillinresistantStaphylococcus aureus in children with no identified predisposing risk. J. American Med. Assoc., 279, 8: 593-598.

Huang, H., Flynn, $\quad$ N.M., King, J.H., Monchaud, C., Morita, M., Cohen, S.H. 2006. Comparisons of Community Associated Methicillin Resistant Staphylococcus aureus (MRSA) and Hospital-Associated MSRA Infections in Sacramento, California. J. Clin. Microbiol., 44,7: 2423-27.

Jevons, M.P. 1961. 'Celbenin'-resistant Staphylococci. British Med. J., 5219: 124-125.

Kac, G., Buu-Hoi, A., Herrison, E., Biancardini, P., Debure, C. 2000. Methicillin resistant staphylococcus aureus nosocomial acquisition and carrier state in a wound care centre. Arch. Dermatol. Res., 136: 7359.

Karri Bauer, A., Jessica West, E., Joan Miquel Balada Llasat, Preeti Pancholi, Kurt Stevenson, B., Debra Goff, A. 2010. An antimicrobial stewardship program's impact with rapid polymerase chain reaction methicillin resistant Staphylococcus aureus/S. aureus blood culture test in patients 
with $S$. aureus bacteremia. Clin. Infect. Dis., 51,9: 1074-80.

Kluytmans, J., Belkum, A.V., Verbrugh, H. 1997. Nasal carriage of Staphylococcus aureus: Epidemiology, underlying mechanisms and associated risks. Clin. Microbiol. Rev., 10,3: 505-520.

Madani, T.A. 2002. Epidemiology and Clinical features of methicillinresistant Staphylococcus aureus in the University Hospital, Jeddad, Saudi Arabia. Canadian J. Infect. Dis., 13,4: 245-250.

Mathanraj, S., Sujatha, S., Sivasangeetha, K., Parija, S.C. 2009. Screening for methicillin-resistant Staphylococcus aureus carriers among patients and health care workers of a tertiary care hospital in south India. Indian J. Med. Microbiol., 27,1: 62-4.

Millar, B.C., Prendergast, B.D., Moore, J.E. 2008. Community-associated MRSA (CA-MRSA): An emerging pathogen in infective endocarditis. $J$. Antimicrobial Chemother., 61:1-7.

Moreillon, P., Que Y A, Glauser M P., Staphylococcus aureus (including Stapylococcal toxic shock) in Mandell, Doughlas and Bennett's. Principles and practice of Infectious disease 6th ed. Churchill Livingstone, 2005; 23212351.

Naimi, T. S., K. H. LeDell, D. J. Boxrud, A. V. Groom, C. D. Steward, S. K. Johnson, J. M. Besser, C. O’Boyle, R. N. Danila, J. E. Cheek, M. T. Osterholm, K. A. Moore, and K. E. Smith., Epidemiology and clonality of community-acquired methicillinresistant Staphylococcus aureus in Minnesota, 1996-1998.Clinical Infectious Diseases; 33,7 :990-996.

Naimi, T.S., LeDell, K.H., Como-Sabetti K, Borchardt SM, Boxrud DJ, Etienne J, Johnson SK, Vandenesch F, Fridkin S, O'Boyle C, Danila RN, Lynfield R., Comparison of community and health care associated methicillin- resistant Staphylococcus

aureus infection. J. American Medical

Association; 290,22: 2976-84.

National Committee for Clinical Laboratory Standards. Methods for dilution antimicrobial susceptibility tests for bacteria that grow aerobically, 2nd edn. Approved standard. M7-A2. National Committee for Clinical Laboratory Standards, Villanova, PA.

Pai, V., Rao, V.I., Rao, S.P. 2010. Prevalence and antimicrobial susceptibility pattern of MRSA isolates at a tertiary care hospital in Mangalore, South India. $J$. Laboratory Physicians, 2,2: 82-84.

Patel, A.K., Patel, K.K., Patel, K.R., Shah S, Dileep P., Time trends in the epidemiology of microbial infections at a tertiary care center in west India over last 5 years. J. Association of Physicians of India, 8: 37-40.

Popovich, K.J., R.A. Weinstein, and B. Hota. 2008. Are community associated methicillin-resistant Staphylococcus aureus (MRSA) strains replacing traditional noso-comial MRSA strains? Clin. Infect. Dis., 46, 6:787794.

Rajaduraipandi, K., Mani, K.R., Panneerselvam, P, Mani M, Bhaskar M, Manikandan P.., Prevalence and antimicrobial susceptibility pattern of MRSA: A multicentre study. Indian J. Med. Microbiol., 24(1): 34-8.

Sader, H.S., Farrell, D.J., Jones, R.N. 2010. Antimicrobial susceptibility of Grampositive cocci isolated from skin and skin-structure infections in European medical centres. Int. J. Antimicrobial Agents, 36, 1 : 28-32.

Sangeeta Joshi, Pallab Ray, Vikas Manchanda, Jyoti Bajaj, D.S. Chitnis, Vikas Gautam, et al. 2013. Methicillin resistant Staphylococcus aureus (MRSA) in India: Prevalence \& susceptibility pattern. Indian Network for Surveillance of Antimicrobial Resistance (INSAR) group, India, Indian J. Med. Res., 363-369. 
Seema Oommen, Rony George, Nisha Kurian, Jose Paul., A comparison of Hospital and Community acquired Methicillin resistant Staphylococcus

aureusinfections in a tertiary care hospital. Pushpagiri Med. J., 1,2.

Shanthi, M., Uma Sekar. 2009. Antimicrobial susceptibility pattern of Methicillin resistant staphylococcus aureus at Sri Ramachandra medical centre. Sri Ramachandra J. Med., 2, 2.

Shapiro, A., Raman, S., Johnson, M., Piehl M., Community-acquired MRSA infections in North Carolina children: prevalence, antibiotic sensitivities, and risk factors. North Carolina Med. J., 70,2: 102-07.

Stevenson, K.B., Searle, K., Stoddard, G.J., Samore, M.H. 2005. Methicillinresistant Staphylococcus aureus and vancomycin-resistant enterococci in rural, western United States. Emerging Infect. Dis., 11: 895-903.

Tambekar, D.H., D.V. Dhanorkar, S.R. Gulhane and M.N., Dudhane. 2007. Prevalence and antimicrobial susceptibility pattern of Methicillin resistantstaphylococcus aureus from healthcare and community associated sources. African J Infect. Dis., 1,1: 52 56.
Thomas, M. 2008. File., Methicillinresistant Staphylococcus aureus (MRSA): focus on communityassociated MRSA. Southern African J. Epidemiol. Infect., 23,2: 13-15.

Vysakh, P.R. and Jeya, M.A. Comparative Analysis of Community Acquired and Hospital Acquired Methicillin Resistant Staphylococcus aureus. J. Clin. Diag. Res., 7,7: 1339-1342.

Walsh, T.J., Viahov, D., Hansen, S.L., Sonnenberg, E., Khabbaz, R., Gadacz, T., Standiford, H.C. 1987. Prospective microbiologic surveillance in control of nosocomial methicillin resistant Staphylococcus aureus. Infect. Control, 8,1: 7-14.

Warren, D.K., Shukla, S.J., Oslen, M.A., Kollef, M.H., Hollen beak, C.S., Cox, M.J., Cohen, M.M., Fraser, V.J. 2003. Outcome and attributable cost of ventilator-associated pneumonia among intensive care unit patients in a suburban medical center. Critical Care Med., 31,5: 1312-17.

Zinderman, C., Conner, B., Malakooti, M., LaMar, J., Armstrong, A., Bohnker, A. $2004 . \quad$ Community-acquired methicillin-resistant Staphylococcus aureus among military recruits. Emerging Infect. Dis., 10, 5: 941-4.

\section{How to cite this article:}

Rajani Ranganath and G.S. Vijaykumar. 2016. Analysis of Health Care Associated MRSA and Community Acquired MRSA and its Risk Factors. Int.J.Curr.Microbiol.App.Sci. 5(12): $733-$

744. doi: http://dx.doi.org/10.20546/ijcmas.2016.512.084 